\title{
Using phosphate to increase feeding consumption in termite Coptotermes formosanus
}

\author{
Hiroto Suhara* ${ }^{*}$
}

\begin{abstract}
Termites are ecologically significant in positive and negative ways; their role in breaking down debris greatly benefits forest environments, but this activity renders them a pest in domestic environments. This study examines the effect of nutrition on the feeding preference of termite Coptotermes formosanus Shiraki. Among 11 nutrition options tested, dipotassium phosphate (DKP) most significantly increased feeding consumption in the multiple feeding choice test. The mean feeding amount of the DKP-treated sample was 2.5-fold higher than that of the deionized water-treated control. This result suggests that termite colonies are deficient in phosphorus, and an additional supply of phosphate can promote feeding. The result of a no-choice feeding test using DKP shows that DKP does not promote feeding in a small number of termites. The results obtained in this study suggest that phosphorus is needed in termite colonies, making DKP especially effective. DKP will help to improve bait technology, because it is inexpensive and safe for both humans and the environment.
\end{abstract}

Keywords: Baiting, Coptotermes formosanus, Dipotassium phosphate, Feeding preference, Pest control

\section{Introduction}

Termites are of great ecological importance because of their ability to recycle wood and other plant materials by breaking down cellulose. However, when they began to destroy artificial wood or wooden products such as homes, buildings, and other commercial products, they become serious economic pests. Subterranean termites are one of the most important termite pests in the world with a widespread global distribution [1,2]. Therefore, effective control methods for termites have been established and considerable efforts have been made for controlling them.

Currently, the bait system, which is a method for controlling subterranean termites, has become a common commercially developed approach [3-5]. Baiting is environmentally sound and utilizes very small amounts of

*Correspondence: suhara-hiroto@pref.miyazaki.lg.jp

Miyazaki Prefectural Wood Utilization Research Center, 21-2 Hanaguri,

Miyakonojo, Miyazaki 885-0037, Japan insect toxins, but these toxicants still potentially have harmful effects on other insects, such as honeybees, or mammals, including humans. Reducing the use of toxic chemicals and/or increasing the efficacy of baiting are environmentally and economically preferable.

As a means of improving baiting, several studies have examined the effects of attractants that can direct subterranean termites to the bait station. Reports on the influence of the foraging behavior of Formosan subterranean termites are as follows: wood decayed by brown rot fungi attract termites [6-8]; sucrose, yeast, or a urea solution entice termites to the drenched substance [9]; and Summon Preferred Food Source disks or its extractives improve tunneling speed and rate of infestation to stations $[10,11]$. The sports drink Gatorade ${ }^{\mathrm{TM}}$ also increased the rate of tunneling [11]. Extracts from leaves of Melaleuca leucadendra L. attracted termites and extracts from the leaves of clove [Syzygium aromaticum (L.) Merr. \& L.M. Perry] demonstrated trail-following activity [12].

\section{Springer Open}

c The Author(s) 2020. This article is licensed under a Creative Commons Attribution 4.0 International License, which permits use, sharing, adaptation, distribution and reproduction in any medium or format, as long as you give appropriate credit to the original author(s) and the source, provide a link to the Creative Commons licence, and indicate if changes were made. The images or other third party material in this article are included in the article's Creative Commons licence, unless indicated otherwise in a credit line to the material. If material is not included in the article's Creative Commons licence and your intended use is not permitted by statutory regulation or exceeds the permitted use, you will need to obtain permission directly from the copyright holder. To view a copy of this licence, visit http://creativeco mmons.org/licenses/by/4.0/. 
Increasing the feeding consumption of termites is another proven method of improving baiting efficacy. To accelerate termite feedings, the use of baits such as wood, including decayed [6,7] or steamed [13] wood, toilet paper rolls [14], and cork [15] have proven effective. Many studies have been conducted to identify certain chemicals that increase the feeding consumption of termites. The chemicals that have been identified and patented as feeding stimulants for use in termite baiting are as follows: D-aspartic and L-glutamic acid [16], hydroquinone $[17,18]$, other forms of saccharides [19, 20], ergosterol [21, 22], and steroid derivatives [23]. However, in tests that compared consumption by Coptotermes formosanus Shiraki of filter paper disks treated with the abovementioned chemicals versus control disks over a range of concentrations, only ergosterol acted as a feeding stimulant [22]. Thus, ergosterol has been incorporated into a cellulose-based bait matrix for termite control [24].

Optimal foraging theory postulates that animals are able to choose their food according to nutritional needs to optimize fitness [25-27]. There are significant differences in the nutrient composition between termites and wood. The ash contents of wood (sapwood and main trunk) ranged from 0.2 to $2.1 \%$ [28-30], while the ash contents of termite workers reached $3.72 \%$ for Nasutitermes spp. [31], 9.90\% for Nasutitermes takasagoensis (Shiraki) [32], 7.494\% for C. formosanus, and $8.850 \%$ for Reticulitermes speratus Kolbe [33]. The main components of ash are phosphorus, potassium, calcium, and magnesium as well as trace amounts of metal elements (minerals) such as aluminum, iron, zinc, sodium, copper, and silicic acid. As shown by Yoshimura et al. [34], the phosphorus, sulfur, chlorine, and sodium contents in $C$. formosanus were more than tenfold higher than those of Japanese red pine (Pinus densiflora Sieb. \& Zucc.). Hence, the author hypothesized that some (or one) of these elements are (or is) constitutively insufficient in termites or termite colonies. In addition, the effects of these elements on the feeding consumption of the subterranean termite C. formosanus, which is one of the most important pests, were examined.

This study aims to find novel compounds that aid effective bait use by promoting termite feeding through the addition of insufficient nutrition.

\section{Methods}

\section{Termites}

Coptotermes formosanus was used for the test in the ongoing study. Mature termites were collected on the Living-Sphere Simulation Fields (LSF) of Research Institute for Sustainable Humanosphere (RISH), Kyoto University located at Hioki City, Kagoshima Prefecture,
Japan, with pine stick traps. Termites were gently separated from the stick and immediately used in the laboratory test. Mature termites were also obtained from a laboratory colony maintained at a temperature of $28 \pm 2{ }^{\circ} \mathrm{C}$ and relative humidity greater than $80 \%$ under dark in the Deterioration Organisms Laboratory (DOL) at the RISH, Kyoto University.

\section{Materials}

To test the feeding preference of termites for different nutrients, termites were confined to a sheet of nutrienttreated filter paper (qualitative filter paper model 9, AS ONE Co., Osaka, Japan) in a choice test. Initially, the filter paper was cut in $2 \mathrm{~cm}$ squares, with five papers layered and joined by needleless stapler (approximately $0.15 \mathrm{~g}$ ). A paper stack was treated with one of each nutrient solution. The following reagents were used as nutrients: ammonium sulfate, calcium chloride, dipotassium phosphate (DKP), disodium phosphate, L-glutamic acid, potassium chloride, sodium chloride (FUJIFILM Wako Pure Chemical Corporation, Osaka, Japan), hydroxyapatite (Kishida Chemical Co., Ltd., Osaka, Japan), $5^{\prime}$-inosinic acid (as inosin 5'-monophosphate disodium salt hydrate; Tokyo Chemical Industry Co. Ltd., Tokyo, Japan), and 5'-guanylic acid (Combi-Blocks Inc., San Diego, USA). The required amount or optimal concentration of nutrients for termites is difficult to predict. Nutrition solution concentrations were defined as $50 \mathrm{mmol} / \mathrm{L}$, because general buffer concentrations ranged from 10 to $100 \mathrm{mmol} / \mathrm{L}$ in biology, and $0.3 \%(\mathrm{w} / \mathrm{v} ; 50 \mathrm{mmol} / \mathrm{L}) \mathrm{NaCl}$ were used as saline for termites, such as C. formosanus [35]. All chemicals used in the study, except for umami ingredients and hydroxyapatite, were tested with this concentration to determine whether they were optimum (Table 1).

A $250-\mu \mathrm{L}$ nutrient solution was adsorbed on filter paper and dried in the oven at $105^{\circ} \mathrm{C}$ for the initial weight measure. Nutrient-treated filter paper was stabbed by pin on 2.5 -cm-square vinyl chloride sheets (3-mm thickness) and placed into a test container randomly.

Natural sea sand for multiple-choice feeding tests was collected from a beach in Miyazaki Prefecture, Japan. The collected natural sea sand was washed with tap water until supernatant was clear and then rinsed with deionized water. After drying by oven at $105^{\circ} \mathrm{C}$, the sand was autoclaved at $120{ }^{\circ} \mathrm{C}$ for $20 \mathrm{~min}$. For no-choice feeding test, sea sand (300-600 $\mu \mathrm{m}$; FUJIFILM Wako Pure Chemical Corporation) was used. Sea sand was autoclaved at $120^{\circ} \mathrm{C}$ for $20 \mathrm{~min}$ before use.

\section{Multiple-choice feeding test}

Between 3.5 and $4 \mathrm{~g}$ of termites (approx. 1200-1300 termites), including both workers and soldiers (soldier ratio 
Table 1 Nutrition concentration used in this study

\begin{tabular}{llll}
\hline Nutrient category & Treatment & Molarity (mol/L) & $\begin{array}{l}\text { Concentration (\%; } \\
\text { w/v) }\end{array}$ \\
\hline Phosphorus & Dipotassium phosphate $\left(\mathrm{K}_{2} \mathrm{HPO}_{4}\right)$ & 0.87 \\
& Disodium phosphate $\left(\mathrm{Na}_{2} \mathrm{HPO}_{4}\right)$ & 0.05 & 0.71 \\
& $5^{\prime}$-Guanylic acid $\left(\mathrm{C}_{10} \mathrm{H}_{14} \mathrm{~N}_{5} \mathrm{O}_{8} \mathrm{P}\right)$ & 0.05 & 0.36 \\
& $5^{\prime}$-Inosinic acid $\left(\mathrm{C}_{10} \mathrm{H}_{11} \mathrm{~N}_{4} \mathrm{Na}_{2} \mathrm{O}_{8} \mathrm{P}\right)$ & $0.01^{*}$ & 0.39 \\
Phosphorus-calcium & Hydroxyapatite $\left[a p p r o x .3 \mathrm{Ca}_{3}(\mathrm{PO} 4)_{2} \cdot \mathrm{Ca}(\mathrm{OH})_{2}\right]$ & $0.01^{*}$ & 1 \\
Nitrogen & Urea $\left(\mathrm{CH}_{4} \mathrm{~N}_{2} \mathrm{O}\right)$ & 0.05 & 0.30 \\
& L-Glutamic acid $\left(\mathrm{C}_{5} \mathrm{H}_{9} \mathrm{NO}_{4}\right)$ & 0.01 & 0.15 \\
Calcium & Calcium chloride $\left(\mathrm{CaCl}_{2}\right)$ & 0.05 & 0.55 \\
Sulfur-nitrogen & Ammonium sulfate $\left[\left(\mathrm{NH}_{4}\right)_{2} \mathrm{SO}_{4}\right]$ & 0.05 & 0.66 \\
Salt & Potassium chloride $(\mathrm{KCl})$ & 0.05 & 0.37 \\
& Sodium chloride $(\mathrm{NaCl})$ & 0.05 & 0.29 \\
- & Deionized water & & {$[16]$} \\
\hline
\end{tabular}

Concentrations were adjusted to that of L-glutamic acid, since it acts as an umami ingredient

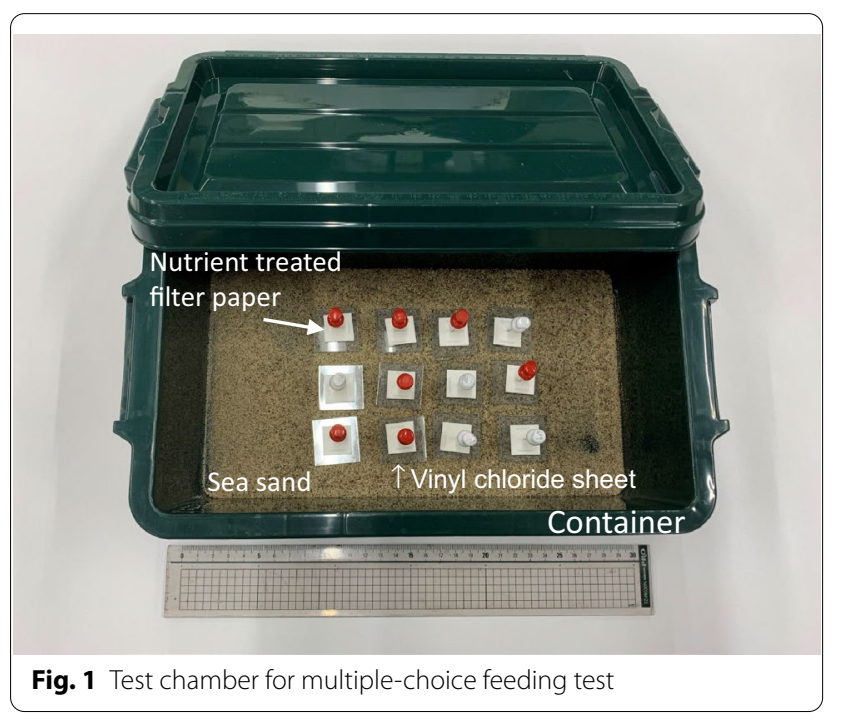

less than 20\%), were used for one trial. Seven replicates were carried out for this test. Termites were introduced into a 4-L home container $(158 \times 283 \times 95 \mathrm{~mm}$ inner size, ST box \#7, Astage Co. Ltd., Niigata, Japan). The container was prepared by spreading $135 \mathrm{~g}$ of sterilized natural sea sand containing $30 \mathrm{~mL}$ of deionized water in advance and placing the test samples on it (Fig. 1). After the container was covered with lid, tests were performed at $25^{\circ} \mathrm{C}$ until the non-treatment control sample lost more than $20 \%$ (up to $50 \%$ ) of its weight (14-25 days). During the test, deionized water was sprayed as appropriate, and the samples' position was replaced at random once a week to avoid bias in feeding by collective behavior. The filter papers were removed from the container when the test was finished and then dried in the oven at $105^{\circ} \mathrm{C}$. The weight loss of each paper was determined. Statistical analysis was carried out using HAD software version 16 [36]. The data were analyzed by one-way analysis of variance, and the results were shown as $F(\mathrm{df} 1, \mathrm{df} 2)=F, p$, and $\eta^{2}=$ partial $\eta^{2}$. F means test statistic (F value) which was derived by degree of freedom (df1 and df2). $p$ means $p$ value in statistical testing. In addition, $\eta^{2}$ means correlation ratio which shows strength of association derived by partial $\eta^{2}$. The method of Holm [37] was used to compare food consumption among the treated and control paper filters.

\section{No-choice feeding test}

The acrylic test tube $(6 \mathrm{~cm}$ high by $7.4 \mathrm{~cm}$ diameter) was first prepared and sealed with a 5-mm-thick gypsum (New Plastone, GC Co., Tokyo, Japan) bottom covered with $10 \mathrm{~g}$ of sea sand containing $2 \mathrm{~mL}$ of deionized water, and then, test samples were placed on top. The weight of 100 workers and 10 soldier termites was measured, and the termites were introduced in an acrylic test tube. A set of treated samples and a nontreated sample were placed into a 4-L home container with a paper towel (Kimtowels, Nippon Paper Crecia Co., Ltd.) on the bottom (Fig. 2). After the container was covered with rid, tests were performed at $25{ }^{\circ} \mathrm{C}$. During the test, dead termites were checked every 2 days, and they were removed immediately. Deionized water was sprayed as appropriate. After a 14-day period, the filter papers were removed and dried in the oven at $105{ }^{\circ} \mathrm{C}$. The weight loss of each paper was determined. The number of surviving termites was checked, and their weight was measured. Five replicates were carried for this test. Statistical analyses were carried out by Student's $t$ test. 


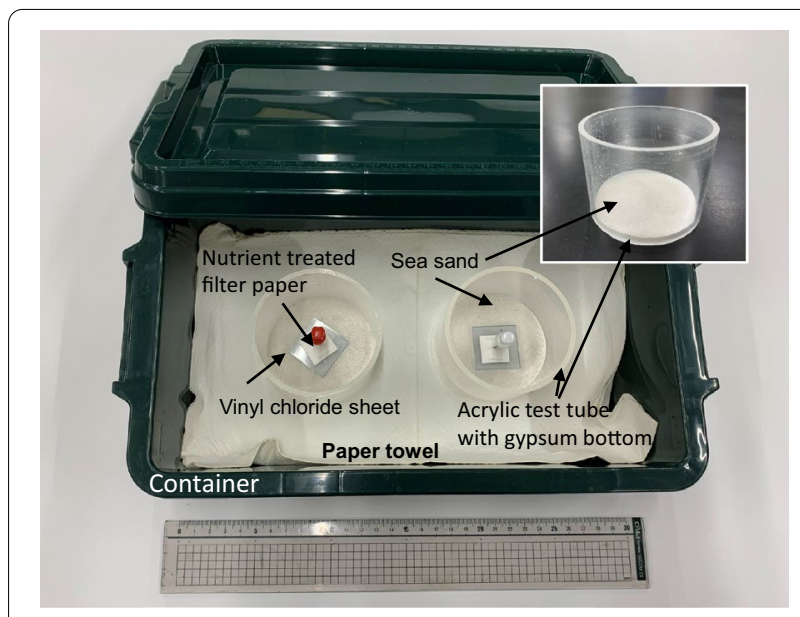

Fig. 2 Test chamber for no-choice feeding test

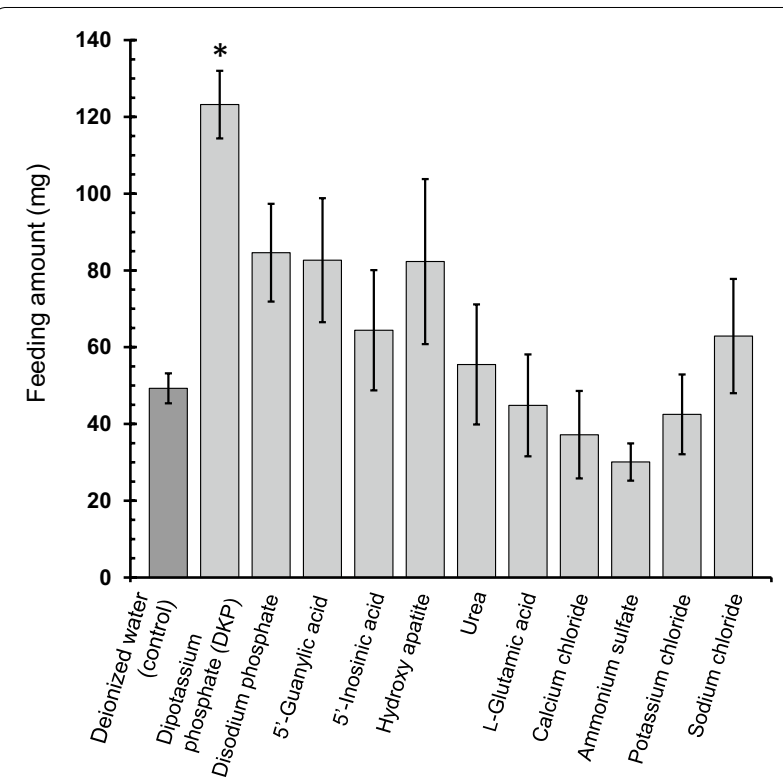

Fig. 3 Total feeding amount (with standard error) of filter paper treated with 11 nutrients or deionized water (control) by Coptotermes formosanus Shiraki under a multiple-choice feeding test. The column with an asterisk is significantly different $(p<0.01)$ from the control using Holm mean separation

\section{Results}

\section{Multiple-choice feeding test}

Total food consumption was significantly different between nutrient-treated samples and the control ( $F$ $\left.[11,66]=4.557, p<0.01, \eta^{2}=0.432\right)$. Of the 11 nutrients tested, only DKP significantly increased consumption compared with the deionized water-treated control $(p<0.01)$ (Fig. 3). The mean feeding amount for the DKPtreated sample $(123.2 \mathrm{mg})$ was 2.5 -fold higher than that of the deionized water-treated control (49.3 mg).

\section{No-choice feeding test}

According to the results of the multiple-choice feeding test, no-choice feeding test was conducted using only DKP. In five trials, the weight losses of termites using the non-treatment control filter paper were more than $20 \%$ (up to 30\%). As shown in Table 2, mean filter paper consumption in the no-choice test was not significantly different between the DKP-treated sample and the deionized water-treated control. Mean mortality and mean termite body weight fluctuation rate were also not significantly different between the treated sample and the control.

\section{Discussions}

Phosphorus (phosphate) is a nutrient essential to life for all species, including Formosan subterranean termites, as it is a component of nucleic acid. Moreover, it also acts as a primary energy source (adenosine triphosphate), a signal molecule (second messenger) of cells (cyclic adenosine monophosphate), and a coenzyme, which has critical functions in most of living things.

Results of the present study indicate that C. formosanus preferred filter paper containing DKP (Fig. 3). The results suggest that $C$. formosanus may feed preferentially on food sources high in phosphate and take a proactive role in supplying the colony with needed phosphate. This is also inferred by the results of the no-choice feeding test (Table 2). No significant differences were observed in feeding amount, mortality, or body weight fluctuation in the test using a restricted number of termites. It is presumed that the phosphate was saturated among a small

Table 2 Feeding amount, mortality, and termite body weight fluctuation rate of no-choice feeding test

\begin{tabular}{|c|c|c|c|c|}
\hline & Treatment & Control & Difference & $\begin{array}{l}\text { Paired } \\
\text { sample } t \text { test } \\
p \text { value }\end{array}$ \\
\hline Feeding amount (mg) & $39.8 \pm 1.8$ & $41.5 \pm 2.5$ & -1.7 & 0.58 \\
\hline Mortality (\%) & $8.3 \pm 1.4$ & $7.4 \pm 1.5$ & 0.9 & 0.66 \\
\hline $\begin{array}{l}\text { Termite body weight fluctuation rate } \\
(\%)\end{array}$ & $-11.2 \pm 3.3$ & $-11.9 \pm 2.3$ & 0.7 & 0.87 \\
\hline
\end{tabular}


number (110) of termites; thus, the increase in feeding was not observed in this test.

The author's group previously reported [38] that some calcium phosphate compounds possibly accelerated decomposition of sugi [Cryptomeria japonica (Thunb. ex L.f.) D.Don] log wood by termites in the field. The mechanism or effective compounds were not clear at that time. From the results of the present study, the previous report seems to suggest that phosphate increases feeding of termite. Although the mean feeding amount of other phosphates including hydroxyapatite-a compound of calcium phosphate-was higher than that of the control, they were not significant. The amount of phosphate released from hydroxyapatite was considered insufficient because of its low water solubility. There is no appropriate idea about the other phosphates at this time; thus, further confirmation is needed, for example, change concentrations.

The addition of nitrogen, calcium, sulfate, and salts did not promote termite feeding in the present study. As it is unclear whether the concentration in the present study was appropriate, further study is needed to determine whether those nutrients promote termite feeding.

As mentioned in the "Introduction", this study aimed to find novel compounds that promote termite feeding by adding insufficient nutrition, thereby helping to use baiting effectively. It is expected that our results capable for practical use in "bait" since feeding amount of DKP is 2.5-fold higher than that of deionized water-treated filter paper that equals as toilet paper roll used in bait system [14]. DKP is inexpensive, easily available from chemical companies, and commonly used as a food additive, fertilizer, and buffering agent. As a food additive, DKP is categorized by the United States Food and Drug Administration as generally recognized as safe (listed as "potassium phosphate dibasic") [39]. Using DKPs is easier than using the previously reported certain amino acid, decayed or steamed wood and its extractives from steamed wood $[6,7,13,16,40]$. Furthermore, DKP can probably be used together with those amino acid, decayed wood and steamed wood or its extractives because they cannot compensate for the phosphorus deficiency. The addition of DKP will improve the efficiency of the bait system and allow a decrease in the usage of toxic chemicals.

The use of sustained release compounds, such as calcium phosphate as previously reported [38], should be considered when used under wet conditions because DKP is highly soluble in water.

Though the effect of DKP and optimal condition to use of DKP should be verified by baiting in the field, these results have a possibility that DKP is preferable for both chemical companies and the environment because chemical companies can simultaneously save baiting drug costs and reduce the risk of environmental pollution from leaking insect toxicants.

\section{Conclusions}

The study's findings suggest that DKP is an important alternative to chemical methods for treating termite infestations. DKP effectively accelerates feeding and is inexpensive and environmentally safe. These results can improve the efficiency and efficacy of bait systems in addressing termite problems. For example, the results suggest that if DKP is impregnated, then the same level of insecticidal effect can be expected even at half the amount of the drug. Alternatively, it can effectively detect termites and reduce damage to wooden structures.

Confirming the feeding-preference activity of phosphorus to other termite species, especially subterranean termites, is necessary. Currently, another study is conducting tests using $R$. speratus, which will be reported elsewhere. Simultaneously, the future study aims to verify the effect of performing field tests by incorporating DKP into the actual bait method and realize the results of the research.

\section{Abbreviations \\ DKP: Dipotassium phosphate; DOL: Deterioration Organisms Laboratory; LSF: Living-Sphere Simulation Fields; RISH: Research Institute for Sustainable Humanosphere.}

\section{Acknowledgements}

I would like to thank Professor Tsuyoshi Yoshimura of the RISH, Kyoto University and Associate Professor Takuro Mori of Hiroshima University for their valuable comments and technical assistance. The author would like to thank Enago (www.enago.jp) for the English language review.

\section{Authors' contributions}

HS designed and performed the experiments, analyzed the data, and drafted the manuscript. The author agreed to be personally accountable for the contributions and to ensure that the questions are accurate and add integrity to any part of the work.The author read and approved the final manuscript.

\section{Funding}

This study was partly supported by the DOL/LSF Inter-University Collaborative Project (2019DOL/LSF-12, 30DOL-LSF-12, 29DOL/LSF-10) under the Department of Collaborative Research Programs of the RISH, Kyoto University.

\section{Availability of data and materials}

All data in this study are available from the corresponding author on reasonable request.

\section{Competing interests}

The author declares no competing interests.

Received: 25 September 2020 Accepted: 1 December 2020

Published online: 14 December 2020

References

1. Henderson G (2008) The termite menace in New Orleans: did they cause the floodwalls to tumble? Am Entomol 54:156-162

2. Rust MK, Su NY (2012) Managing social insect of urban importance. Ann Rev Entomol 57:355-375 
3. Cabrera BJ, Su NY, Scheffrahn RH, Koehler PG (2002) Termite baits. University of Florida Cooperative Extension. https://www.researchgate.net/publi cation/265742937_Termite_Baits_1. Accessed 4 Mar 2020

4. Lenz M, Evans TA (2002) Termite bait technology: perspectives from Australia. In: Proceedings of the 4 th international conference on urban pests. Pocahontas Press, Charleston, USA, pp 7-10.

5. Su NY (2011) Technological needs for sustainable termite management. Sociobiology 58:229-239

6. Esenther GR, Gray DE (1968) Subterranean termite studies in southern Ontario. Can Entomol 100:827-834

7. Esenther GR, Beal RH (1979) Termite control: decayed wood bait. Sociobiology 4:215-222

8. Su NY (2005) Directional change in tunneling of subterranean termites (Isoptera: Rhinotermitidae) in response to decayed wood attractants. J Econ Entomol 98:471-475

9. Waller DA, Morlino SE, Matkins N (1999) Factors affecting termite recruitment to baits in laboratory and field studies. In: Robinson WH, Rettich F, Rambo W (eds) Proceedings of the 3rd international conference on urban pests, Prague: 597-600.

10. Cornelius ML, Lax AR (2005) Effect of summon preferred food source on feeding, tunneling and bait station discovery by the Formosan subterranean termite (Isoptera: Rhinotermitidae). J Econ Entomol 98:502-508

11. Cornelius ML, Osbrink WLA (2008) Effect of bait supplements on the feeding and tunneling behavior of the Formosan subterranean termite (Isoptera: Rhinotermitidae). Sociobiology 51:497-511

12. Indrayani Y, Muin M, Adilla C, Yoshimura T (2018) Attractiveness of subterranean termite Coptotermes formosanus to plant leaf extracts. Biodiversitas 19:1176-1180

13. Doi S (2001) A trial of preventing termite attacks using wood and its constituents. Jpn J Environ Entomol Zool 12:103-109 (in Japanese)

14. French JRJ, Robinson PJ (1981) Baits for aggregating large numbers of subterranean termites. J Aust Ent Soc 20:75-76

15. French JRJ, Robinson PJ, Ewart DM (1986) Mound colonies of Coptotermes formosanus (Isoptera) eat cork in preference to sound wood. Sociobiology 11:303-309

16. Chen J, Henderson G (1996) Determination of feeding preference of Formosan subterranean termite (Coptotermes formosanus Shiraki) for some amino acid additives. J Chem Ecol 22:2359

17. Reinhard J, Lacey ML, Lenz M (2002) Application of the natural phagostimulant hydroquinone in bait systems for termite management (Isoptera). Sociobiology 39:213-230

18. Reinhard J, Lacey ML, Ibarra F, Schroeder FC, Kaib M, Lenz M (2002) Hydroquinone: a general phagostimulating pheromone in termites. J Chem Ecol 28:1-14

19. Ohmura W, Doi S, Aoyama M, Ohara S (1999) Components of steamed and non-steamed Japanese larch (Larix leptolepis (Sieb. et Zucc.) Gord.) heartwood affecting the feeding behavior of the subterranean termite, Coptotermes formosanus Shiraki (Isoptera: Rhinotermitidae). Holtzforschung 53:569-574

20. Saran RK, Rust MK (2005) Feeding, uptake, and utilization of carbohydrates by western subterranean termite (Isoptera: Rhinotermitidae). J Econ Entomol 98:1284-1293

21. Henderson GJ, Chen J, Laine RA (1999) Compositions and methods for detecting and killing termites. US Patent 5,874,097, 23 Feb 1999.

22. Cornelius ML (2003) Evaluation of semiochemicals as feeding Stimulants for the Formosan subterranean termite (Isoptera: Rheinotermidae). Sociobiology 41:583-591

23. Galinis DL, Strnad SP (2000) Methods and compositions for attracting and controlling termites. US Patent 6,093,389 25 Jul 2000.

24. Rojas MG, Morales-Ramos JA (2001) Bait matrix for delivery of chitin synthesis inhibitors to the Formosan subterranean termite (Isoptera: Rhinotermitidae). J Econ Entomol 94:506-510
25. Westoby M (1974) An analysis of diet selection by large generalist herbivores. Am Nat 108:290-304

26. Whelan C, Brown JS, Schmidt KA, Steele BB, Willson MF (2000) Linking consumer-resource theory and digestive physiology: application to diet shifts. Evol Ecol Res 2:911-934

27. Simpson SJ, Sibly RM, Lee KP, Behmer ST, Raubenheimer D (2004) Optimal foraging when regulating intake of multiple nutrients. Anim Behav 68:1299-1311

28. Sekino N, Kofujita H, Abe K, Higashino T (2011) Characterizing calorific value of coniferous bark chips in terms of elemental and chemical composition and its practical range as boiler fuel. Mokuzai Gakkaishi 57:101-109 (in Japanese)

29. Ochi S, Ozaki M, Maki T (2008) Date of element analysis on herbaceous and woody plants (Modified version). Technical Note of PWRI (Technical Memoranda of PWRI) 4095. ISSN 0386-5878 (in Japanese). https://www. pwri.go.jp/team/imarrc/research/tech-info/tech4095.pdf. Accessed 4 Mar 2020

30. Haraguchi T (1985) Composition of wood. In: Haraguchi T, Terashima N, Usuda M, Koshijima T, Sakai K, Morohoshi N, Teratani F, Kai Y, Shimizu K, Sakakibara A (eds) Chemistry of Wood. Buneido Press, Tokyo. ISBN 4830040378 (in Japanese)

31. Oyarzun SE, Crawshaw GJ, Valdes EV (1996) Nutrition of the Tamandua: I. Nutrient composition of termites (Nasutitermes spp.) and stomach contents from wild tamanduas (Tamandua tetradactyla). Zoo Biol 15:509-524

32. Itakura S, Moriyama H, Fukuda M, Tanaka H, Enoki A (2011) Nutritional composition of higher termites, Nasutitermes takasagoensis (Shiraki) and Odontotermes formosanus (Shiraki) (Blattodea: Termitidae). Jpn J Environ Entomol Zool 22:87-91 (in Japanese)

33. Itakura S, Okuda J, Utagawa K, Tanaka H, Enoki A (2006) Nutrition value of two subterranean termite species Coptotermes formosanus Shiraki and Reticulitermes speratus (Kolbe) (Isoptera: Rhinotermitidae). Jpn J Environ Entomol Zool 17:107-115 (in Japanese)

34. Yoshimura T, Kagemori N, Kawai S, Sera K, Futatsugawa S (2002) Trace elements in termites by PIXE analysis. Nucl Instr Meth Phys Res B 189:450-453

35. Inoue Y, Sugio K, Tokuda G, Yasuda I, Yoshimura T (2012) Termites and education. In: Yoshimura T, Itakura S, Iwata R, Ohmura W, Sugio K, Takematsu Y, Tokuda G, Matsuura K, Miura T (eds) Termites researches in Japan: from biodiversity to control. Kaiseisha Press, Otsu (in Japanese)

36. Shimizu H (2016) An introduction to the statistical free software HAD: Suggestions to improve teaching, learning and practice data analysis. Journal of Media, Information and Communication 1:59-73. http://hdl. handle.net/11150/10815. Accessed 4 Mar 2020

37. Holm S (1979) A simple sequentially rejective multiple test procedure. Scand J Statist 6:65-70

38. Suhara H, Nakatani M, Mori T, Ito T (2015) Acceleration of biodeterioration by termite on residual thinnings. MOKUZAI HOZON (Wood Protection) 41:119-128 (in Japanese)

39. United States Food and Drug Administration (2019) Generally Recognized as Safe (GRAS) Substances (SCOGS) Database. Silver Spring. https ://www.fda.gov/food/generally-recognized-safe-gras/gras-substances -scogs-database. Accessed 4 Mar 2020

40. Ohmura W, Doi S, Ohara S (2000) Acceleration of boric acid uptake into Coptotermes formosanus Shiraki using steamed larch heartwood extracts in a laboratory test. Jpn J Environ Entomol Zool 11:1-8

\section{Publisher's Note}

Springer Nature remains neutral with regard to jurisdictional claims in published maps and institutional affiliations. 